\title{
Cultures in Collision: Traditional Knowledge and Euro-Canadian Governance Processes in Northern Land-Claim Boards
}

\author{
GRAHAM WHITE ${ }^{1}$
}

(Received 30 November 2005; accepted in revised form 24 July 2006)

\begin{abstract}
This paper analyzes how traditional knowledge (TK) is used by two of the co-management and regulatory boards established under the comprehensive land-claim agreements in Canada's territorial North: the Nunavut Wildlife Management Board (NWMB) and the Mackenzie Valley Environmental Impact Review Board (MVEIRB). A comparison of the defining characteristics of Western "Weberian" bureaucracy, which sets the framework within which these and other boards operate, and central tenets of traditional northern Aboriginal culture highlights the oftentimes stark incompatibilities between what amount to different worldviews. Both boards are shown to have made substantial and sincere efforts at incorporating TK into their practices. The NWMB, with its wildlife-focused mandate, is better able to accommodate TK in its work than is the MVEIRB, which deals with complex legal regulatory issues. Both, however, are limited in their capacity to fully incorporate TK into their operations by the exigencies of the modern bureaucratic state.
\end{abstract}

Key words: traditional knowledge, traditional environmental knowledge, co-management, land claims, environmental regulation, bureaucracy, wildlife management, government boards

RÉSUMÉ. Le présent document analyse la manière dont les connaissances traditionnelles (CT) sont utilisées par deux des offices de cogestion et de réglementation fondés en vertu des accords exhaustifs de revendication territoriale dans le Nord canadien, soit l'office Nunavut Wildlife Management Board (NWMB) et l'office Mackenzie Valley Environmental Impact Review Board (MVEIRB). La comparaison des caractéristiques déterminantes de la bureaucratie « weberienne » occidentale, qui établit le cadre de fonctionnement de ces offices et d'autres offices, et des principes fondamentaux de la culture autochtone traditionnelle du Nord fait ressortir les incompatibilités parfois difficiles entre ce qui se résume à être des visions différentes du monde. Les deux offices ont fait des efforts considérables et sincères pour intégrer les connaissances traditionnelles à leurs pratiques. Le NWMB, avec son mandat axé sur la faune, est mieux en mesure de tenir compte des connaissances traditionnelles dans son travail que le MVEIRB, qui s'occupe de questions réglementaires et juridiques complexes. Cela dit, ces deux organismes ont une capacité limitée quand vient le temps d'intégrer entièrement les connaissances traditionnelles à leur exploitation, limitations qui découlent des exigences de l'État bureaucratique moderne.

Mots clés : connaissances traditionnelles, connaissances environnementales traditionnelles, cogestion, revendications territoriales, réglementation environnementale, bureaucratie, gestion de la faune, offices gouvernementaux

Traduit pour la revue Arctic par Nicole Giguère.

\section{INTRODUCTION}

Discussions of Aboriginal traditional knowledge (TK) often emphasize differences between TK and Western science in terms of fundamental intellectual orientation, methodology, and substantive findings. Some observers, however, suggest that the two scientific paradigms need not necessarily be in conflict and indeed, with good will and open-mindedness, can complement one another. To take but one symbolically and substantively important example, in 1998 the Yukon Fish and Wildlife Management Board organized a major conference bringing together First Nations hunters and elders along with government and academic scientists to talk about TK and wildlife management. The conference's title, "Two Eyes: One Vision," captured well the sense that TK and Western science can and should complement one another (Urquhart, 2001)

This paper explores a different and arguably more intractable incompatibility, not between TK and Western science, but between TK and the values and procedures of Western-style governance. It does so through the lens of governmental institutions that have a special need for and concern with TK, the co-management and regulatory boards established under Canada's comprehensive land claims.

After many decades of systematic exclusion from governmental processes, Canada's Aboriginal peoples have in recent years begun to play an important role in government decisions and policy development affecting them. Especially notable has been the emergence of substantial and sophisticated Aboriginal "self-government" regimes. The

\footnotetext{
${ }^{1}$ Department of Political Science, University of Toronto at Mississauga, 3359 Mississauga Road North, Mississauga, Ontario L5L 1C6, Canada; gwhite@ chass.utoronto.ca

(C) The Arctic Institute of North America
} 
problems faced by these Aboriginal governments are essentially of a kind with those encountered by any government-developing capacity, securing adequate financial resources, managing internal political conflict, and the like. In some ways, the thorniest and most important problems are found at the intersection of Aboriginal governments and conventional "public" governments (i.e., the Government of Canada and those of the provinces, territories, and municipalities). The co-management and regulatory boards established under the various modern-day treaties-comprehensive land claims-signed between Aboriginal peoples, Canada, and the provinces and territories, are a prime example. These boards represent a compromise between the desire of Aboriginal claimant groups to maximize their control over wildlife and environmental issues central to their existence and the insistence of the federal government that the public interest in resource issues requires public governance. Accordingly, the boards exist as "institutions of public government" but with extensive guaranteed Aboriginal participation. Indeed, on many boards the majority of members are Aboriginal, and on a few, all members are Aboriginal. Disagreement exists as to the overall effect of these boards, but few would dispute that, as Natcher et al. (2005:240) have written of co-management regimes, they are "restructuring indigenous-state relations more broadly."

If the objective is to bring meaningful Aboriginal influence to bear on important wildlife and environmental issues, should not numerical domination of the boards suffice? (Of course, a necessary condition is that the boards themselves wield real power; this is indeed the case.) Governance is not simply a matter of raw numbers; it is very much a function of the rules-formal and informal-and the organizational culture of the institutions of governance. In turn, rules, institutions, and cultures are deeply rooted in worldviews and values. Herein lie the problem and the focus of this paper.

In the world of politics and government, how an institution gathers information, processes ideas, reaches decisions, and formulates and implements policies may be just as important, if not more important, than the actual decisions it makes and the policies it develops. (And, of course, the "how" profoundly affects the "what.") Thus Aboriginal influence on the boards depends a good deal on their operating according to Aboriginal principles and values.

In the context of wildlife management and environmental protection-the central missions of most land-claim boards-Aboriginal principles and values are frequently understood in terms of "traditional knowledge" (TK), though in practice, this typically means "'traditional ecological knowledge" (TEK), a narrower concept. In Nunavut these ideas and values are rendered as Inuit Qaujimajatuqangit (IQ)-literally "that which has been long known by Inuit." A number of boards have made an explicit and serious commitment to including TK in their activities, analyses, and deliberations. In Nunavut, incorporating IQ into all manner of governance is the policy of the Government of Nunavut, but land-claim boards have also taken IQ principles on board.

While the prospects for and possible means of melding TK and Western science are of prime importance for landclaim boards, they are not the subject of this paper. Rather, I examine here a more subtle and perhaps more intractable problem. I address, within the context of land-claim boards, what has been termed "a deeper question ... whether the historical values and practices of Dene or Inuit society, as these have survived the massive changes of the last century, are at all compatible with modern governing procedures, mass societies, and public bureaucracies" (Abele, 1997:iv).

More specifically, I ask in this paper whether fundamental incompatibilities exist between Aboriginal worldviews and the values (implicit as well as explicit) of the Western rational-bureaucratic model of public administration, which suffuses land-claim boards. This question is important because it focuses attention on a key issue: do the norms and operating procedures that structure the boards' activities represent a barrier to thoroughgoing, genuine Aboriginal influence on board processes?

I explore these issues through case studies of two important land-claim boards, the Nunavut Wildlife Management Board (NWMB) and the Mackenzie Valley Environmental Impact Review Board (MVEIRB).

Previous research into wildlife co-management institutions in northern Canada has found that TK plays at best a minor role in the operation and decisions of boards such as the Beverly and Qamanirjuaq Caribou Management Board (BQCMB) and the Ruby Range Sheep Steering Committee, and that overall Aboriginal influence on these boards is limited (Cizek, 1990; Kendrick, 2000; Rodon, 2003; Nadasdy, 2003, 2005; Spak, 2005) Land-claim boards, however, are very different from bodies such as the BQCMB in that their existence and their authority derive directly from comprehensive land-claim agreements. Since the comprehensive claims are constitutionally protected under section 35 of the Constitution Act, 1982, so too the boards enjoy quasi-constitutional status. Land-claim boards wield considerable decision-making clout by virtue of "negative option" provisions, which typically stipulate that a board recommendation takes effect unless a government minister formally vetoes it within a relatively short time span (usually 60-90 days). Nominally most landclaim boards have only advisory powers, but only rarely are their recommendations overturned by government; in effect, they have become important players in major wildlife and environmental issues. And while land-claim boards complain about underfunding by the federal government, their staff and financial resources are far superior to those of non-land-claim boards such as the BQCMB.

Accordingly, land-claim boards are not only substantively important sites in terms of gauging the influence of TK, they represent perhaps the best opportunity for imbuing public, non-Aboriginal governmental institutions with TK. In other words, if the land-claim boards cannot 
successfully integrate TK into their processes and decisions, it is unlikely that another public government institution would fare any better.

\section{METHODS}

This paper is based largely on primary documents issued by the Nunavut Wildlife Management Board and the Mackenzie Valley Environmental Impact Review Board (many of which are available on the boards' web sites), analyzed through the lens of literature on traditional knowledge and co-management in northern Canada. Further context on land-claim boards in general and on the NWMB and MVEIRB in particular was gleaned through observation of various meetings and public hearings: meetings of the Inuvialuit Game Council and the Wildlife Management Advisory Committee (NWT) in Inuvik in December 2001 and the NWMB in Igloolik in September 2005. I attended public hearings held by the Yukon Water Board in February 2003 and June 2006 and those held by the MVEIRB in Hay River in February 2004 on the Cameron Hills extension project. I also attended the TK Workshop that the MVEIRB organized in Yellowknife in November 2002. Direct quotations or paraphrases of participants' comments from this workshop are taken from the notes I took there.

This paper is part of a larger project on the operation and influence of the boards established by the land-claim agreements in northern Canada funded by the Social Sciences and Humanities Research Council of Canada. Though this paper does not draw directly from them, it is broadly informed by the several dozen unstructured personal interviews I have conducted with members, former members, and staff of various land-claim boards, with officials of the federal and territorial governments, and with elected and appointed officials of various Aboriginal organizations. These interviews, conducted on a not-for-attribution basis, took place in Inuvik, Iqaluit, Ottawa-Hull, Yellowknife, and Whitehorse; not all touched on TK or IQ.

\section{A LAND-CLAIM BOARD AT WORK - THE CAMERON HILLS HEARINGS}

The specifics of land-claim board decisions vary a good deal and doubtless every application or issue before a board is in some measure unique. Accordingly, the following account of a public hearing held in February 2004 in Hay River, Northwest Territories by the Mackenzie Valley Environmental Impact Review Board is not held out as in any way "typical." It is nonetheless instructive.

Paramount Resources, a mid-size oil company based in Calgary, wished to substantially expand its seismic, drilling, and ultimately its extraction activities in the Cameron Hills just north of the Alberta-Northwest Territories border, southwest of Great Slave Lake. It applied to the
Mackenzie Valley Land and Water Board (MVLWB) in April 2003 for the requisite permits and licences. The MVLWB conducted a preliminary screening of the project, a process that included consultations with 21 governmental, Aboriginal, and local community organizations. In May of that year, citing "the potential for public concern and significant environmental impacts related to cumulative effects," the MVLWB referred the proposal to the MVEIRB for an environmental assessment, which began almost immediately (MVEIRB, 2004b).

This process entailed extensive gathering of technical data, communications with Paramount, government departments as well as the communities and First Nations organizations close to the potentially affected area. Most of this proceeded by way of compilation and exchange of documents. However, as part of its review of the project, the MVEIRB decided to hold a public hearing in Hay River, the nearest substantial centre to the area in question. Notices of the meeting were sent to various federal and territorial government departments, to potentially affected individual First Nations, and to other Aboriginal organizations; the media were also alerted and publicity directed to the general public. The day before the public hearings began, Board members and staff (joined by members and staff of the MVLWB) held an informal community meeting in Kakisa, the closest First Nations community to the Cameron Hills.

Elements of informality were evident in the Hay River hearings: as is typical in the North, almost no one wore jackets and ties, but jeans were much in evidence. Participants mingled freely during breaks for coffee and cookies. Overall, however, the process could hardly be called informal.

To walk into the good-size hotel meeting room where the hearing took place was to encounter an imposing setting with an unmistakable aura of formality and bureaucratic officialdom. Tables for the official participants, piled high with documents, all but filled the room. Six Board members, supported by four staff, a consultant, and the Board lawyer, sat at a table in one corner of the room, facing the participants. The Paramount contingent, at another table, consisted of nine people. Other tables held nine officials representing four federal departments and the ten staff sent by three departments of the Government of the Northwest Territories. Yet another group of tables was set aside for Aboriginal organizations. Four individual First Nations were represented at the hearing, as were two more broadly based Aboriginal organizations and one community resource management board (not all attended in person; several were represented by a consultant). Five members and two staff of the MVLWB, who attended as observers, occupied yet another table. A handful of chairs for the public were set out along one wall. All told, an intimidating, unwelcoming environment for anyone not used to such settings.

The hearing began, as is customary in the North, with a prayer, one of the Aboriginal Board members offering the prayer in his language. Brief welcoming and introductory 
remarks by the Chair of the Board stressed that the hearing was not designed to be adversarial and that "the purpose of questioning is to seek clarification of points made in these presentations, and not to engage in debate or adversarial cross-examination" (MVEIRB, 2004a, vol. 1:13).

Virtually all of the presentations, as well as the questioning, took place in English, with simultaneous translation available into Slavey. One Aboriginal leader spoke in Slavey, which was translated into English. Elders brought to the hearings by one Aboriginal group spoke in English, but indicated that they would have been more comfortable and could have spoken more effectively in Chipewyan; however, no translation was available. One First Nation prefaced its submission with a 50-minute video about traditional usage of the land and animals in the area in question. Presenters and questioners were given all the time they required; no one was rushed.

Paramount made the first formal presentation; over the next two days, each organization (governmental or Aboriginal) that had registered in advance was given the opportunity to make a formal statement (most, but not all, did so). Questioning followed each presentation; Board members were afforded the first chance to ask questions, but generally preferred to listen to the exchanges among the other participants. Every registered organization was invited to comment on or question the organization that had just made its presentation. Once all registered participants had had their say, Board staff could ask questions, which they did on occasion to clarify technical points or to crystallize points of agreement or disagreement. Finally, the "public" was called upon to voice any comments or questions. For most of the hearing, the "public" consisted of a solitary University of Toronto political scientist, who declined to put forward any opinions or questions. Occasionally, one or two real members of the public would wander into the hearing room, but few stayed for any length of time and none spoke.

Most of these exchanges were civil and many were technical, but some had a clear confrontational edge to them and were highly political in nature. At one point, for example, a Paramount representative referred to the local First Nations as "neighbours"; this incited an Aboriginal leader to take the Paramount "newcomers" to task and to stipulate that the First Nations were not Paramount's neighbours, but their "landlords." The same Aboriginal leader also objected to Paramount's conceptual approach, based as it was on such non-Aboriginal concepts as "wildlife" and "remoteness." Even more telling, for purposes of this paper, was a sharp clash between Paramount and the First Nations' representatives about "traditional usage" of lands that stood to be most affected by the exploration and drilling. According to Paramount, since the First Nations could not produce lists of persons who had hunted or trapped in this area for the past few years, this meant that the land was not actually in use by nearby First Nations. The elders and the consultant explained that harvesting had occurred in the area in years past and might well again, depending on the animals' migration patterns and on the harvest in nearby regions and that accordingly, they still used and occupied the land. Paramount officials aggressively and repeatedly challenged this view - and the elders who put it forward - to the visible annoyance of at least one of the Aboriginal Board members. One of the First Nations explicitly commented in its closing statement that some of Paramount's questions were disrespectful.

That the Board held an informal community meeting and two days of formal public hearings should not obscure the dominance of documentary evidence in the Cameron Hills process. By the time the public registry was closed in March 2004 as the Board prepared to make its decision, some 234 separate documents had been logged (all of which were available for public inspection). Some were no more than one-page faxes proposing or confirming arrangements for meetings, document exchanges and the like, but many were extensive technical documents or detailed position papers. Virtually all were in English.

In June 2004 the Board issued an 84-page report, in English, presenting its analysis and recommendations to the federal Minister of Indian Affairs and Northern Development. The Board concluded that the project should be allowed to proceed, subject to a number of conditions (set out in the recommendations) ranging from air quality monitoring to measures for mitigating effects on fish habitat, to negotiation of a socioeconomic agreement between Paramount and affected communities (MVEIRB, 2004b:55-57). As the minister was not prepared to accept all the recommendations, protracted negotiations ensued between the minister and the Board on possible modifications to certain recommendations. Agreement was reached in March 2005 and the Board's amended conditions were forwarded to the appropriate agencies for implementation.

\section{TRADITIONAL KNOWLEDGE, TRADITIONAL ECOLOGICAL KNOWLEDGE, AND INUIT QAUJIMAJATUQANGIT}

The literature on traditional knowledge (TK, or in some formulations, indigenous knowledge, IK) is vast, a good deal of it having been generated by writers focusing on the Canadian North. Berkes' (1999:8) oft-quoted definition well captures the central elements of TK: "A cumulative body of knowledge, practice and belief, evolving by adaptive processes and handed down through generations by cultural transmission, about the relationship of living beings (including humans) with one another and with their environment." At the same time, epistemological and methodological difficulties abound in understanding TK and in relating it to Western modes of thought (Wenzel, 1999; Cruikshank, 2004; Huntington, 2005). Battiste and Henderson (2000:134-135) flatly state that "Indigenous knowledge must be understood from an Indigenous perspective using Indigenous language; it cannot be understood from the perspective of Eurocentric knowledge and 
discourse." Or, as the Kluane woman quoted by Nadasdy (2003:63) put it, "it's not really 'knowledge' at all; it's more a way of life."

Among the issues identified in the literature are the centrality of language, carrying as it does very different conceptual frameworks and ways of thinking and knowing; skepticism as to the validity of comprehensive, allencompassing ideas about TK (leading some to prefer to think in terms of "local knowledge"); and misconceptions about what is "traditional" about TK.

"What is traditional about traditional ecological knowledge," Battiste and Henderson (2000:46) write, "is not its antiquity, but the way it is acquired and used." The word "traditional" carries misleading connotations, suggesting customs and beliefs "frozen at a particular point in time (usually the distant past)" (Nadasdy, 2003:120) with limited relevance to current-day realities. This is one reason why in Nunavut the recently developed phrase "Inuit Qaujimajatuqangit" (IQ)—defined as "the combining of the traditional knowledge, experience and values of Inuit society, along with the present Inuit knowledge, experience and values that prepare the way for future knowledge, experience and values"-has come to be preferred over "TK" (GN, 2002:4). Nonetheless, since outside Nunavut traditional knowledge seems the term of choice in both governmental and Aboriginal circles, it will be used in this paper.

The terms "traditional knowledge" and "traditional ecological knowledge (TEK)" are often used interchangeably. Recognizing that dividing what is a unified conceptual framework into discrete categories is very much a Western approach, I distinguish for the purposes of this paper between TK (and IQ) and TEK. It is surely correct that "the heritage of an indigenous people is not merely a collection of objects, stories and ceremonies, but a complete knowledge system with its own concepts of epistemology, philosophy, and scientific and logical validity" (Daes, quoted in Battiste and Henderson, 2000:19). It is nonetheless useful to recognize, as does Abele (2006), that TK comprises at least three interrelated components: 1) a distinctive political and social perspective, rooted in shared history; 2) local knowledge; and 3) ethical and cosmological knowledge.

This formulation underlines an important point, which is not always adequately addressed in treatments-especially governmental treatments - of TK. Traditional Aboriginal knowledge and values about the natural environment, including detailed understandings of the land and the behaviour of animals in addition to ethical codes governing the proper relations of humans to the land and the animals - 'traditional ecological knowledge'are clearly crucial elements of TK. However, TK is a far broader concept than TEK (rendered in this way), encompassing as it does analyses and prescriptions for all manner of social interaction among people as well as deeply spiritual and philosophical precepts (often implicit and unspoken). A Yukon First Nation citizen whose legal practice encompasses TK and intellectual property rights puts it this way: "the spiritual connection never leaves TK" (B. MacDonald, pers. comm. 2006). I argue that while significant strides have been made, at least in the two boards examined below, towards giving due attention to TEK, the more fundamental aspects of TK collide head-on with the bureaucratic matrix in which the boards are embedded.

One of the most prominent themes in the literature on TK highlights the different conceptual frameworks, methodologies and underlying values of TK and Western science, though to be sure, the view that the two can be complementary has its proponents. So too, a good deal of literature examines the use of TK in environmental assessment processes and in co-management regimes (Stevenson, 1996; Usher, 2000; Berkes et al., 2005; Ellis, 2005). Most of this literature, however, focuses on the natural environment and human interaction with it; social relations, widely defined, receive rather less attention. Even harsh critics such as Stevenson, who maintains (2004:68) "it would be difficult to conceive a more insidious form of cultural assimilation than co-management as currently practiced in northern Canada," and who attacks the appropriation and abuse of TK in co-management regimes, largely frames his criticism in terms of the dominance of the approaches and findings of Western science. In short, the subject of this paper, the interplay of TK and the values and processes of Western governance, has attracted relatively little academic attention.

\section{TK AND IQ AND NORTHERN LAND-CLAIM BOARDS: TWO CASE STUDIES}

\section{Mackenzie Valley Environmental Impact Review Board}

The Mackenzie Valley Environmental Impact Review Board (MVEIRB) was created by the Mackenzie Valley Resource Management Act (MVRMA), a federal statute passed in 1998 to implement provisions of the Gwich'in and Sahtu comprehensive claims. Its remit is to conduct initial environmental assessments and, if required, full environmental impact reviews on proposed developments (roads, mines, pipelines, seismic explorations and the like) throughout the Northwest Territories, save in the Inuvialuit Settlement Area defined under the 1984 Inuvialuit Final Agreement. Actual permits are issued not by the MVEIRB but by separate boards, also under the MVRMA: the Gwich'in Land and Water Board, the Sahtu Land and Water Board, the Wek'èezhìi Land and Water Board, and the Mackenzie Valley Land and Water Board.

A few years into their work it became evident to Board members, especially Aboriginal members, that despite their strong commitment to incorporating TK into Board practices, more effort was needed to develop practical measures for doing so. This issue was further complicated by the provision in the Act that defines environmental 
impact not simply in terms of effects on the physical environment but also as "any effect on the social and cultural environment or on heritage resources" (Canada, 1998 c25 s11). Accordingly, the Board hired a TK Coordinator, one of whose first duties was to organize a workshop in November 2002 to consider how to bring TK into its environmental assessment processes.

Originally conceived as a small gathering, the meeting generated such wide interest across the Northwest Territories that it became necessary to hire the largest meeting room in Yellowknife to accommodate all those who wished to attend. Most of the nearly 100 delegates or observers were Aboriginal, many representing Aboriginal organizations; officials from governmental agencies (including land-claim boards) were also present in significant number. The latter, mainly non-Aboriginal, primarily came to listen; the discussion and comments mostly involved Aboriginal participants, some of whom spoke in Slavey or Dogrib, which was translated for those unable to understand. Few issues were resolved or practical procedures devised for incorporating TK into northern environmental assessment. Still, the meeting provided an opportunity for Aboriginal leaders and elders to set out clearly their views on the nature and importance of TK. As well, it identified many points of principle and practice that the Board would need to address in developing its approach to TK. Two overriding conclusions were evident from the meeting. First, the Board was serious in trying to determine how to incorporate TK into its work. Second, this would be a huge task, fraught with difficulty.

One obvious source of difficulty is language. Again and again, Aboriginal participants at the workshop stressed the inextricable intertwining of language and TK. "Expressing some aspects of TK in English is practically impossible," said one; another argued "we're faced with the problem of [having to deal with] non-Dene people and non-Dene systems to make ourselves understood ... if you want to understand us [and TK] you [non-Dene] must learn our language." And yet, as was evident in the Cameron Hills extension hearings, virtually all MVEIRB proceedings are in English as are all key documents; some proceedings, but few documents, are translated into one or more Dene languages. Translation, when available, is often a poor substitute for understanding the unique conceptual apparatus every language carries. An especially problematic concern with TK is rendering subtle Aboriginal concepts into English and technical English terms into Aboriginal languages. In recognition of this concern, the Board sponsored a three-day Translators' Workshop devoted to working out concepts and terminology which would at least partially bridge the linguistic gap between English and the Aboriginal languages for purposes of environmental assessments or impact reviews.

Some months after the Yellowknife workshop, the Board released a draft set of Traditional Knowledge Guidelines for comment. A revised draft was published in November 2004 and again comments were solicited. The final version was published in July 2005. Various considerations and recommendations from these guidelines, as well as comments from the Yellowknife workshop, are incorporated into the analysis below. At this point only the basic conceptualization of TK in the Guidelines will be examined.

The preamble sets out the Board's understanding of the role of TK in its work: "In order to ensure that aboriginal cultures, values and knowledge play an appropriate role in its decisions, the Review Board is committed to fully consider any traditional knowledge brought forward in its proceedings" (MVEIRB, 2005b:4). Arguing that TK is an evolving concept that admits of no easy formulation, the Guidelines do not offer a precise definition. However, three "particularly important elements" of TK are outlined. First, "Knowledge about the environment"- essentially factual knowledge about the natural environment (in the terms set out above, TEK). Second, "Knowledge about use and management of the environment," which includes "cultural practices and social activities, land use patterns, archeological sites, harvesting practices, and harvesting levels, both past and present." In light of the discussion below, use of the term "management" is noteworthy. The third component is the most interesting and the most problematic. "Values about the environment" involve preferences as well as moral and ethical positions about the environment and are in large measure determined by Aboriginal spirituality (MVEIRB, 2005b:6).

While the essential purpose underlying the Guidelines is the integration of TK into Board practices and procedures, as will become evident below, the document well illustrates the inherent incompatibilities between the Aboriginal worldview of TK and the Euro-Canadian legal-bureaucratic model of governance within which the Board functions.

\section{Nunavut Wildlife Management Board}

The importance the Inuit accord wildlife issues is underlined by two telling facts about the Nunavut Wildlife Management Board (NWMB). First, the details of the structure, mandate, and operation of the Board are set out in the text of the Nunavut land-claim agreement itself. This is noteworthy since other Nunavut claim boards warrant not much more than a few paragraphs. Second, the article in the claim establishing the NWMB was one of the first negotiated.

The Board is designed to realize some of the claim's central objectives, relating to "rights of Inuit to participate in decision-making concerning the use, management and conservation of land water and resources ... and rights to participate in decision-making concerning wildlife harvesting" (DIAND/TFN, 1993:1). It engages in a wide range of activities: it sets limits on harvesting of various species; allocates harvest quotas; approves wildlife management plans; conducts, supervises, and approves research projects; develops guidelines for various activities (guiding, harvesting techniques); and so on. 
Given these powers and responsibilities, it is hardly surprising that the Board accords central importance to IQ. Indeed, its vision statement proclaims the goal of "conserving wildlife through the application of Inuit traditional knowledge and scientific knowledge" (NWMB, 2004:39). The language of the land claim underlines the importance of IQ principles in the Board's operations, requiring for example that the wildlife management regime "recognizes Inuit systems of wildlife management" and the "need for an effective role for Inuit in all aspects of wildlife management, including research" (DIAND/TFN, 1993: Article 5.1.2).

A visit to the Board's web site makes its commitment to IQ immediately evident (http://www.nwmb.com). All documents-annual reports, board minutes, research studiesare available in Inuktitut, though to be sure concepts such as written minutes of meetings, annual reports, and the like reflect Western bureaucratic rather than IQ principles. Enjoying a prominent position on the Board's home page are links to major studies commissioned or conducted by the Board: the Bowhead Knowledge Report, the Southeast Baffin Beluga Study, and the mammoth Nunavut Wildlife Harvest Study, all of which provided the basis for important Board decisions on harvest levels and quotas. Significantly, all three incorporated extensive use of Inuit researchers employing IQ methods and interpretations.

The Board has not developed formal guidelines for incorporating IQ into its work, though it committed to do just that at its September 2005 meeting in Igloolik. To date, it has preferred to bring IQ perspectives to bear through the experience of board members and the extensive involvement of Inuit at the community level, for example through the local Hunters and Trappers Organizations, which have close links with the Board. In turn, this entails practices designed to encourage and facilitate participation in Board activities by those-especially elderswith intimate knowledge of the land and the animals. The priority given to Inuktitut and the Board's Rules of Practice for Public Hearings, discussed in the next section, are important elements of this objective.

For all that it is evident that while the NWMB has successfully integrated IQ and Western science into the empirical knowledge base upon which its decisions rest, important elements of its structure and operation remain essentially rooted in the Western bureaucratic paradigm. A self-assessment carried out by the Board suggests as much, maintaining that the Board

has brought together the best of the Inuit way and the best of the Anglo-European way; it has brought together traditional knowledge and modern science; it has brought together a knowledge of the land and animals, based on thousands of years of experience, and a knowledge of the workings of modern government and its bureaucracy. (NWMB, 1999b:4)

That the Board found it necessary to develop an 11-page document setting out public hearing procedures is a clear indication of the bureaucratic framework within which it operates. At the same time, its efforts at minimizing the impediments to participation by Nunavummiut hunters and elders unaccustomed to such formalities are evidenced in the fact that it produced not only an Inuktitut version of its procedures, but also an Inuktitut audio summary.

\section{CULTURES IN COLLISION: NORTHERN ABORIGINAL TK AND EUROCANADIAN GOVERNANCE PROCESSES}

That incompatibilities should exist between northern Aboriginal TK and the precepts underpinning the EuroCanadian legal-bureaucratic model will not surprise anyone familiar with the clash of cultures endemic to Aboriginal-state relations in Canada. An extensive literature, for example, highlights the fundamental incongruence between certain Aboriginal ideas and processes of justice and those held or used by Euro-Canadians. Still, an enumeration of how the two worldviews differ is essential to understanding why even land-claim boards with extensive Aboriginal membership and which value TEK cannot be said to incorporate TK.

Despite efforts at imbuing them with the principles and procedures of the so-called "new public management," governmental institutions in Canada-land-claim boards included-are still very much cast in the mold of the classic Weberian bureaucracy. Max Weber (1864-1920) was a prominent German sociologist, whose writings established the basic model by which academics still understand bureaucracy (Weber, 1946; Bendix, 1960). Among its essential features: it is hierarchical, with power concentrated at the top; it operates according to extensive, written, formal, impersonal rules and procedures; authority is based on office-holding rather than on personal attributes; it is based on extensive compartmentalization of functions and division of labour; it is premised on a sharp division between the public and private spheres; employment and promotion within it depend on merit, defined according to formal criteria; "facts" and knowledge are to be ascertained and verified by rigorous, often adversarial, challenging of assertions; decisions are reached through "rational" evaluation of the empirical evidence so gathered; as much information as possible should be made available to all those potentially affected by its actions. (Since the emphasis in this paper is on the bureaucratic rather than the political sphere of governance, such Western principles as majoritarian decision making and delegation of farreaching powers to elected representatives are not considered. Even here, of course, the conventional Western distinction between the political and the bureaucratic is incongruent with Aboriginal approaches to governance.)

Bearing in mind that some are of greater relevance to land-claim boards than others, let us consider these characteristics in terms of their consistency with the values and practices of traditional northern Aboriginal cultures. 


\section{Hierarchical with Power Concentrated at the Top}

A phrase frequently applied to Western bureaucracies, which well captures their fundamental nature is "command and control." The classic Weberian bureaucracy is characterized by a clearly specified hierarchy of positions, with explicitly defined reporting relationships. All members of the organization know who has authority to issue orders to them, just as they know to whom they can issue orders: the higher one's position in the hierarchy, the greater one's power. As well, the powerful positions at the top of the hierarchy are few in number; indeed, typically a single person sits atop the entire organization, with authority over all others, although the few officials in the next rung or two down from the top also wield extensive power. Recent trends in organizational engineering that have produced "flatter" governmental organizations (with fewer levels) have not fundamentally altered their hierarchical design or the concentration of power at the top.

Northern Aboriginal cultures are by no means all of a piece; however, by and large they tend to be egalitarian and non-hierarchical - though, to be sure, powerful "camp bosses" were certainly prominent in parts of the North. Typically, "leaders [in Inuit society] didn't exercise their authority by giving orders or acting superior but rather by giving advice or using their knowledge and experience to guide the group" (Wessendorf, 2001:1). Moreover, in many traditional northern societies those who did exercise authority had circumscribed spheres of influence. The person who led the hunt carried no special authority in matters spiritual, while the person entrusted with dealing with others (such as non-Aboriginal traders or government figures) would not have had influence when it came to hunting or to healing.

\section{Extensive, Written, Impersonal Rules and Procedures}

The hallmark of the Western bureaucracy is extensive reliance on precise, written rules and formal, oftentimes rigid procedures. Officials' discretion is sharply fettered in this way, in part to avoid favouritism or prejudice. Rules are formulated so as to anticipate as much as possible all contingencies and to produce similar outcomes in similar situations. Accordingly, these rules take on enormous complexity, in turn requiring specialized training to understand them and intimate familiarity with bureaucratic culture to cope with them.

Nothing could better illustrate these features than the Mackenzie Valley Resource Management Act, with its 70 pages of staggeringly complex procedures set out in dense legal and technical prose (plus dozens of pages of regulations). Lawyers and experienced bureaucrats navigate the Act with relative ease, but others-well-educated non-Aboriginals, let alone Dene elders with limited English-language skills-find it little short of baffling and impenetrable. Even a much-simplified schematic diagram displaying the basic steps in the permitting process fills an entire page.
TK, by contrast, emphasizes simplicity and flexibility. One principle of IQ, for example, is Qanuqtuurunnarniq/ Kaujimatukanut, "the ability to be creative and flexible and to improvise with whatever is at hand to achieve a purpose or solve a problem" (Nunavut, 2003 c26 s 8 (a)).

The MVEIRB must constantly be concerned with leaving itself open to legal challenges on procedural grounds and thus must conduct its business far more formally than the NWMB, which faces few such concerns. The MVEIRB does attempt to operate as informally as possible, as evidenced in two of its rules of procedure:
30. In conducting its proceedings, the Review Board is not bound by the strict rules of evidence.
31. To the extent consistent with its duty of procedural fairness, the Review Board will emphasize flexibility and informality in its proceedings and in the manner in which it receives information or documents. (MVEIRB, 2005a:6)

As a quick perusal of the other 94 rules (not to mention the pertinent sections of the Act) suggests, however, the Board's capacity to be flexible and informal is sharply circumscribed by the legal framework within which it operates.

Legal imperatives do not loom so large for the Nunavut Wildlife Management Board. One of its rules for public hearings echoes the MVEIRB's aspiration:

The NWMB shall, consistent with the broad application of the principles of natural justice and procedural fairness, emphasize flexibility and informality in the conduct of a hearing. (NWMB, 1999a:9)

While these rules are unquestionably important as a signal of the Board's commitment to bringing IQ into its processes, it is worth noting that at the time of writing, the NWMB had not held any "public hearings." It had visited many communities and held informal community consultations, but it did not designate them as "public hearings." The Board may be reconsidering whether such consultations should not be accorded the status of public hearing.

The NWMB has given itself scope for bringing Qanuqtuurunnarniq/Kaujimatukanut to its hearings:

\footnotetext{
The NWMB may waive or amend any of these Rules, if the Board considers it to be in the interests of fairness. Where any matter arises that is not envisioned by these Rules, the Board shall do whatever it considers necessary, to enable it to deal with the issue in a just manner. (NWMB, 1999a:1)
}

The MVEIRB has a rule which points in a similar direction, though it is framed in more legalistic language and appears less all-encompassing than that of the NWMB: "The Review Board may, in any proceeding, dispense with, vary or supplement these Rules by way of a direction or procedure" (MVEIRB, 2005a:3). 
The emphasis on documents and written rules raises questions about the place of oral communications in the operation of land-claim boards. Traditional northern Aboriginal societies have oral cultures and often convey ideas or information through stories or metaphors (at the Yellowknife TK workshop, one Aboriginal participant explained TK as "listening to the river"). Most boards, including the MVEIRB and the NWMB, employ hearings, where oral evidence is presented and discussed (though oral presentations often amount to little more than reading of documents). And while information and opinion gathered orally are certainly taken seriously, documents are often more extensive and more prominent in board proceedings-as evidenced in the process surrounding the MVEIRB's recommendations on the Cameron Hills extension project.

The NWMB does explicitly place audio recordings on the same footing as written submissions in its hearing Rules, thereby offering elders and others who may have limited facility with written English or Inuktitut the opportunity to present their views to the Board.

Such practices, which facilitate (or inhibit) communications between those with TK and land-claim boards, highlight the central role of language. TK is first and foremost a set of cultural constructs, and culture is inextricably bound up with language. In the Canadian North, the inescapable reality is that rules and procedures are set out in English, even if they are subsequently translated into Aboriginal languages, as is the case with Nunavut boards. Clearly, this puts a premium on facility in English and emphasizes capacity to draft and interpret English documents. By extension, those without strong English language skills, particularly in written English, are disadvantaged (recall the elders who would have preferred to address the Hay River hearings in Chipewyan). Perhaps even more important are the implicit assumptions and conceptualizations inherent in formulating ideas and information in English rather than in Aboriginal languages. Mention was made earlier of the difficulty-some would say impossibility—of conveying important aspects of TK in non-Aboriginal languages.

Still, translation is important, and it is noteworthy that the NWMB requires translation of all short documents (less than six pages) and recordings (less than five minutes) presented to it at hearings, while longer documents or recordings must be accompanied by a translated summary (NWMB, 1999a:7). Meetings of some boards, as illustrated by the Hay River hearings, are conducted largely or entirely in English. Others use Aboriginal languages extensively, especially in Nunavut, where Inuktitut often predominates in board meetings. The NWMB's Operating Procedures, echoing the provisions in the claim, mandate that "the NWMB shall conduct its business in Inuktitut and as required by legislation or policy, Canada's official languages" (NWMB, 2001:20). Nonetheless, with most non-Inuit Board members and staff lacking anything but the most rudimentary Inuktitut skills, communications frequently occur via translation rather than in the form of genuinely bilingual exchanges, where all or most participants speak and understand both languages. And even experienced, professional translators may have lapses; a recent NWMB meeting, for example, was punctuated by complaints from one Inuktitut-speaking board member of unsatisfactory translations.

A rather different, but nonetheless significant illustration of the incompatibility of the formal procedures central to Weberian bureaucracy is to be found in the accountability regimes imposed by the NWMB on local Hunters and Trappers Organizations (HTOs). Since each HTO receives $\$ 76000$ a year from the NWMB, the Board expects an accounting of how the money was spent (just as Ottawa expects the Board to account for the funds it distributes to the HTOs). By normal governmental standards, the reporting requirements are not at all onerous. Still, the upshot is that small local Inuit organizations primarily concerned with wildlife issues find themselves being transformed into bureaucratically constrained organizations. The uneasy relationship between Inuit interested in caribou, seal, and char and the expectations of the modern bureaucratic state is evident in the administrative disarray that has often characterized HTOs (Minogue, 2004, 2005).

\section{Authority Based on Office-Holding}

In the Weberian schema underpinning Euro-Canadian bureaucracies, authority is vested in the office, not the person holding the office. On leaving the office, an official loses authority, which is transferred to the new officeholder. Northern Aboriginal societies accord influence to people for their personal attributes, not their formal position. An important special case of this characteristic is the respect accorded elders on the basis of the wisdom they have acquired through life experiences. This distinction carries less direct relevance to land-claim boards than others examined in this section, but nonetheless underlines important differences in conceptions of authority.

\section{Compartmentalization and Division of Labour}

Like most indigenous cultures, northern Aboriginal societies are holistic. They do not compartmentalize life or the world around them into discrete realms-economic, political, spiritual, and so on. Phenomena cannot be understood in isolation, but only in a very broad context including the physical environment and the spiritual dimension. This contrasts markedly with the Western tendency to conceptualize human relations, as well as relations between humans and the natural environment, in terms of discrete spheres of activity; a telling illustration is the widespread insistence on separation of church and state. At a micro level, the division of labour and task specialization characteristic of Euro-Canadian bureaucracies also runs directly contrary to Aboriginal ways (though of course some division of labour, most notably between men and 
women, characterized traditional northern Aboriginal societies). The division of responsibilities and expertise typically found in government bureaucracies, which might include a polar bear biologist, a caribou specialist, an air quality expert, and others with narrow specializations, is decidedly foreign to Aboriginal people who perforce must know about all manner of animals and their environment (Nadasdy, 2003). Just such a contrast was evident in the hearings into the Cameron Hills project: elders drew upon their wide-ranging familiarity with the area in question, whereas government teams included fisheries biologists, air quality scientists, and various other specialists.

This deep-rooted philosophical divide appears in another important way: though the demarcation may be constantly in flux, Western societies assume a clear distinction between the private and the public. Many aspects of life-such as educational techniques and standards, financial transactions, and other economic activities-are deemed to be in the public domain and thus appropriate subjects for government intervention. Many others, however-relations with friends and relatives, personal habits, and the like-are seen as essentially private matters in which the state normally plays no role. The public-private divide has evident applications in bureaucratic organizations: the work life of the government official is entirely separate from his or her personal life. Traditional northern Aboriginal societies knew no division into public and private realms; this way of characterizing the world and human relations is foreign to Aboriginal people's understanding of the world and their place in it.

One particular element of the disjuncture between holistic Aboriginal worldviews and compartmentalized Western concepts of the world and humanity's place in it has special relevance to land-claim boards, especially those concerned with "managing" wildlife. Western thought sees man as separate from and indeed superior to nature, and thus capable of mastering and managing its components, including wildlife. For northern Aboriginal peoples, humans are part of nature but with no claim to enhanced status over its other elements. Accordingly, the notion that people could "manage" wildlife is alien to Aboriginal understandings.

As Spak (2005) explains in her study of two northern co-management boards, Western society's reductionist worldview compartmentalizes elements of the environment and sees humans as separate from and indeed superior to nature, in turn producing attitudes about resources and 'resource management' starkly different from those held by Aboriginal peoples:

The term resource management itself is a European expression exemplifying European attitudes and approaches toward nature ... in this view a resource is something to be used and controlled by humans ... this anthropocentric attitude is a key component upon which the government resource management rationale is based. The usage of the term "management" in regards to resource activities further conveys the impression that humans actively manage a resource as if they could assign each component of the resource a specific task.

This way of seeing the world and its resources is diametrically opposed to the understandings and paradigms within which many Dene traditionally operate. The most important distinction between European and traditional Dene attitudes towards nature is that the Dene do not see themselves as being separate from or above nature. In this worldview humans are a part of nature. They thus cannot control or manage that of which they are a part, but they can and must regulate their own behaviour in order to ensure the continuation of the balanced reciprocity which exists between them and their surroundings. (Spak, 2005:235)

In short, the very notion that a governmental agency can "manage" wildlife - no matter who serves on it and how much TK/IQ they bring to their work-involves a fundamental contradiction between northern Aboriginal worldviews and the Western bureaucratic paradigm.

\section{Merit}

The Weberian bureaucratic model accords a central place to the "merit principle," whereby officials in an organization are hired and promoted on the basis of merit rather than through favouritism or by virtue of ascriptive characteristics such as ethnicity or gender. At an abstract level, northern Aboriginal societies were typically also merit-based: for example, the best hunter was recognized as the most appropriate choice to lead the hunt. At an operational level, though, a marked divergence is evident. In modern Canadian governments, merit is largely defined in terms of formal credentials, primarily educational achievements and experience in similar organizational environments. Practical experience outside of institutional settings counts for little, yet it is precisely those practical qualifications that are most valued in Aboriginal cultures. The credentialism that characterizes government bureaucracies means that someone with a university biology degree is presumed to possess the expertise needed in developing and implementing government policy, whereas an Aboriginal elder who has spent decades on the land but lacks formal scientific training is not seen in the same light. The Aboriginal perspective, of course, is precisely the opposite.

The NWMB's hearing rules do make special provision for elders:

Recognizing the role of Elders in Inuit society, the NWMB shall provide reasonable opportunity for Elders to speak at a hearing. The Board shall make every reasonable effort to accommodate Elders, with respect to seating, order of appearance, and opportunity to raise matters and to comment on and respond to matters raised at the hearing. (NWMB, 1999a:10) 


\section{Adversarial Challenging of Assertions and "Rational" Evaluation of Evidence}

Northern Aboriginal societies are non-confrontational, with decisions typically reached by consensus after prolonged discussion. Disagreements are expressed in respectful, oftentimes elliptical fashion. The wisdom of elders is accepted without question. The contrast with the aggressive, adversarial approach to expressing disagreement or challenging assertions in Western bureaucratic and legal processes is stark.

Even nominally non-conflictual bureaucratic settings can take on characteristics incompatible with northern Aboriginal practices. Meetings frequently unfold with participants criticizing and defending one another's positions, questioning alleged facts, and interrupting one another. These are generally not acceptable behaviours in northern Aboriginal cultures.

By design the Western legal system is highly adversarial, built on the assumption that "the truth" will come out through the cut and thrust of debate and the challenge of evidence. Assertions are not accepted at face value, but are subject to demands for "proof" according to specified rules of evidence that permit, indeed often encourage, aggressive cross-examination of witnesses and impugning their truthfulness and integrity. Many, though not all, of those who negotiated the land claims or developed and drafted the legislation to implement the claims, such as the MVRMA, were lawyers, and they clearly brought the conceptual apparatus of their profession to bear. And while efforts were made to deal with the problem of excessive legalism and formality, board processes, especially those of regulatory boards like the MVEIRB, are shot through with exactly those characteristics.

In a board hearing, lawyers representing a licence applicant would presume it their right-as indeed it is, in the legal framework underpinning regulatory board processes-to vigorously cross-examine an elder on a TKbased assertion. This certainly occurred at the Hay River hearing. Such practices, however, may not be just discordant with Aboriginal customs: they may be profoundly offensive. As one Aboriginal participant at the Yellowknife workshop put it, "questioning TK is attacking the integrity of the elders ... which is the most disrespectful thing you can do."

The MVEIRB is clearly sensitive to concerns of this nature, yet is constrained by its mandate and legislation. An intriguing illustration emerges from a comparison of the final and penultimate versions of the board's TK Guidelines. The November 2004 draft stipulated that "traditional knowledge submissions do not have to follow the strict rules of evidence as long as the nature of the evidence is relevant to the EIA [Environmental Impact Assessment] process." This statement was immediately followed by the admonition that "the information must be supported and proven by the parties sharing the information." In the final version, this provision was entirely dropped, whereas the following statement survived intact from the draft to the final version: "Traditional knowledge evidence provided to the Review Board during a formal hearing shall be subject to verification in the same manner as all other evidence" (MVEIRB, 2005b:26). (As noted earlier, however, the board does not accept that it is bound by "the strict rules of evidence.")

The NWMB, which need not be especially concernedas must the MVEIRB - with formal rules of evidence, does attempt through its hearing procedures to ensure IQ principles are followed in its meetings, specifying that "the NWMB shall make every effort to ensure that all participants and witnesses at the hearing are treated with respect" (NWMB, 1999a:9).

\section{Maximum Public Release of Information}

Aboriginal communities are often prepared to share their TK with scientists, governments or anyone else who is interested in it, but this is by no means universally the case. Aboriginal people may not wish to provide information to governments or to industry for fear that it will be used in ways contrary to their interests and wishes, for example, in attempts to bolster the case for developments such as mines or oil and gas exploration that might harm the land or interfere with its use. Even more problematic are elements of TK that are simply not to be shared with outsiders; deeply held ethical codes may proscribe any discussion of certain matters with anyone not of the community.

Though Western governments certainly have their secrets, key elements of modern government activity are subject to pervasive requirements of transparency and public access to information. This is very much the case for northern co-management and regulatory boards. Like other regulatory agencies, the MVEIRB maintains a public registry of documents submitted to it in the course of environmental assessments and reviews. Board procedures require that all documents, both routine administrative correspondence and substantive reports, requests and comments, be made public via its registry except in unusual circumstances. The practice followed in the review of the Cameron Hills extension project is standard procedure, with full text of all documents on the registry available via the Internet.

The Board is aware of the potential conflict between the desire not to make public certain elements of TK and the procedural need for openness. Its TK Guidelines provide for the possibility of exempting —on request—particular information from inclusion in the public record. The presumption, however, is that TK will be made public:

The Review Board's acceptance and use of traditional knowledge will be sensitive to the nature and source of the information and it will respect any arrangements made for its collection... public access to information that influences a Review Board decision is an important 
part of a fair process, and the Review Board will carefully consider any requests before granting confidential status to information." (MVEIRB, 2005b:10)

Ultimately, moreover, the decision rests with the Board. In order to agree to an exemption, the Board "must be convinced that significant harm may result from the release of such information, and the onus for showing harm rests with the party seeking to secure confidential status on the information" (MVEIRB, 2005b:10). Giving up control of TK in this manner may not be satisfactory to Aboriginal communities or organizations, which may thus decline to provide it-presumably to the detriment of their interests in the assessment or review process. And of course, such a procedure cannot address issues arising when the TK touches matters that are to be kept in the community.

In addition, Board records are subject to freedom of information requests by way of the federal Access to Information and Privacy Act.

\section{CONCLUSION}

It is evident that both the Mackenzie Valley Environmental Impact Review Board and the Nunavut Wildlife Management Board have made sincere, sustained efforts to bring TK/IQ into their operations. Evident as well is the advantage the NWMB enjoys in this enterprise by virtue of the nature of its mandate. Wildlife conservation and harvesting and related matters such as wildlife research can be seen as modern-day extensions of traditional Inuit pursuits, though of course the "management" framework and other aspects of the Board's activities are decidedly nontraditional. By contrast, it is difficult to imagine licencing and assessing the environmental impact of diamond mines and pipelines as having even the remotest links to traditional Dene activities.

For both boards, while the collection of data reflects TK/IQ methods to varying degrees, and while TEK itself is seriously considered in decision making, the conceptual framework within which the boards operate significantly limits the influence of TK/IQ.

A strong parallel exists with respect to progress on imbuing the Government of Nunavut with IQ, an admittedly far greater challenge. The government's own IQ Task Force makes the point forcefully:

At present there is a chasm-a cultural divideseparating the Inuit Culture on the one side from the Nunavut Government's institutional culture on the other side. (GN, 202:11)

We cannot develop an Inuit government by taking the IQ principles, extracting them from their cultural context (life on the land) and forcing them into a new context (life within the Government of Nunavut). Because the
Inuit culture is much broader than the government, we must incorporate the government into the culture.

This becomes quite clear once we understand that public governments-all public governments-have their own cultural characteristics. When we try to incorporate Inuit IQ into the existing Nunavut Government we create a "culture clash". And, as is usual in all culture clashes, the dominant culture dominates. The Inuit culture is forced to take on the shape of the dominant, rather than the other way round. (GN, 2002:6)

A recent analysis of how environmental regulation boards in the Mackenzie Valley use TK reached the same conclusion:

Initiatives to incorporate traditional knowledge into environmental decision making can be effective only if they strive to address this problem by adapting conventional environmental decision making to aboriginal ways of knowing and doing, rather than the conventional converse. (Ellis, 2005:75)

Based on his study of TEK use in wildlife management in the Kluane region of the Yukon by a non-claims-based co-management board, anthropologist Paul Nadasdy offers a decidedly negative interpretation of the culture clash between First Nations cosmology and the apparatus of the modern state:

Although on the surface land claims and co-management seem to be giving Aboriginal peoples increased control over their lives and land, I argue that these processes may instead be acting as subtle extensions of empire, replacing local Aboriginal ways of talking, thinking, and acting with those specifically sanctioned by the state. (Nadasdy, 2003:9; for a critique see Hunn et al., 2003)

The experiences of Nunavut HTOs, alluded to above, certainly supports this interpretation. And yet it would be a mistake to ignore the substantial gains for Aboriginal people that the claims and the co-management regimes across the North represent (significantly, the co-management board which is the focus of Nadasdy's study is not a land-claim board and wields far less policy clout than land-claim boards).

Clearly, the structure and operation-indeed the very essence-of boards like the MVEIRB and the NWMB are fundamentally rooted in Euro-Canadian governance processes, with all their Weberian bureaucratic characteristics and their legalistic, evidence-testing paradigm. Accordingly they cannot conduct themselves within the allencompassing philosophical/ethical framework that TK/ IQ entails. However, they have made important strides towards incorporating TEK ideas and methods into key elements of their work. 
This paper has made some progress towards answering the key question posed by Natcher et al. (2005:242) about co-management (which also applies to boards engaged in environmental regulation): whether "co-management, as practiced today, represents an institutional structure that is at all compatible with aboriginal value systems." As far as TK/IQ in land-claim boards is concerned, the snowmobile's tank may be seen as half-full or half-empty. Its purpose has been not to denigrate the efforts of boards like the MVEIRB and the NWMB to bring TK to bear in their operations, but to argue that the nature of the modern bureaucratic state, of which they are a part, puts firm limits on just how far such efforts can go.

\section{ACKNOWLEDGEMENTS}

This paper grew out of my presentation to the "First Nations, First Thoughts," conference held at the University of Edinburgh in May 2005. I wish to record my thanks to the dozens of members, staff, and observers of northern land-claim boards, government officials, and representatives of Aboriginal organizations who consented to not-for-attribution interviews with me over the past few years. Special thanks also to the various board staff who answered follow-up questions and provided documents. My thanks also to Gina Cosentino for her expert research assistance. The research reported in this paper was supported by a grant from the Social Sciences and Humanities Research Council of Canada. The paper has benefited substantially from the comments and suggestions of the reviewers and the editors.

\section{REFERENCES}

ABELE, F. 1997. Traditional knowledge in practice. Arctic 50(4): iii-iv.

. 2006. Between respect and control: Traditional indigenous knowledge in Canadian public policy. In: Orsini, M., and Smith, M., eds. Critical policy studies: Contemporary Canadian approaches. Vancouver: UBC Press. 233-256.

BATTISTE, M., and HENDERSON, J.(S.)Y. 2000. Protecting indigenous knowledge and heritage: A global challenge. Saskatoon: Purich.

BENDIX, R. 1960. Max Weber: An intellectual portrait. New York: Doubleday.

BERKES, F. 1999. Sacred ecology: Traditional ecological knowledge and resource management. Philadelphia: Taylor \& Francis.

BERKES, F., HUEBERT, R., FAST, H., MANSEAU, M., and DIDUCK, A., eds. 2005. Breaking ice: Renewable resource and ocean management in the Canadian North. Calgary: University of Calgary Press.

CANADA. 1998. Mackenzie Valley Resource Management Act. Statutes of Canada, c 25.

CIZEK, P. 1990. The Beverly-Kaminuriak Caribou Management Board: A case study of aboriginal participation in resource management. Ottawa: Canadian Arctic Resources Committee.
CRUIKSHANK, J. 2004. Uses and abuses of 'traditional knowledge': Perspectives from the Yukon Territory. In: Anderson, D.G., and Nuttall, M., eds. Cultivating Arctic landscapes: Knowing and managing animals in the circumpolar North. New York: Berghahn Books. 17-32.

ELLIS, S.C. 2005. Meaningful consideration? A review of traditional knowledge in environmental decision making. Arctic 58(1): $66-77$.

GN (GOVERNMENT OF NUNAVUT). 2002. The first annual report of the Inuit Qaujimajatuqanginnut (IQ) Task Force. Iqaluit: Department of Culture, Language, Elders and Youth.

HUNN, E.S., JOHNSON, D.R., RUSSELL, P.N., and THORNTON, T.F. 2003. Huna Tlingit traditional environmental knowledge, conservation and the management of a 'wilderness' park. Current Anthropology 44 (Supp.):S79-S103.

HUNTINGTON, H.P. 2005. 'We dance around in a ring and suppose': Academic engagement with traditional knowledge. Arctic Anthropology 42(1):29-32.

DIAND/TFN (DEPARTMENT OF INDIAN AFFAIRS AND NORTHERN DEVELOPMENT/TUNGAVIK FEDERATION OFNUNAVUT). 1993. Agreement between the Inuit of Nunavut settlement area and Her Majesty the Queen in right of Canada. Ottawa: Minister of Supply and Services.

KENDRICK, A. 2000. Community perceptions of the BeverlyQamanirjuaq Caribou Management Board. Canadian Journal of Native Studies 20(1):1-33.

MVEIRB (MACKENZIE VALLEY ENVIRONMENTAL IMPACT REVIEW BOARD). 2004a. Paramount Resources Ltd. environmental assessment public hearing transcript. Hay River, NT, February 18. Available from MVEIRB, 200 Scotia Centre, 5102 -50th Avenue, Yellowknife, Northwest Territories $\mathrm{X} 1 \mathrm{~A} 2 \mathrm{~N} 7$.

. 2004b. Report of the environmental assessment and reasons for decision on the Paramount Resources Ltd. Cameron Hills Extension Project, EA03-005. Available from MVEIRB, 200 Scotia Centre, 5102-50th Avenue, Yellowknife, Northwest Territories X1A 2 N7.

2005a. Rules of procedure for environmental assessment and environmental impact review proceedings. Available online at http://www.mveirb.nt.ca/reference_lib/guidelines.php.

2005b. Guidelines for incorporating traditional knowledge in environmental impact assessment. Yellowknife: MVEIRB. Available online at http://www.mveirb.nt.ca/reference_lib/ guidelines.php.

MINOGUE, S. 2004. Iqaluit HTO produces sketchy financial records. Nunatsiaq News, December 17.

. 2005. Financial statements a first for Amarok HTA. Nunatsiaq News, December 16.

NADASDY, P. 2003. Hunters and bureaucrats: Power, knowledge and aboriginal-state relations in the southwest Yukon. Vancouver: UBC Press.

- 2005. The anti-politics of TEK: The institutionalization of co-management discourse and practice. Anthropologica 47(2):215-232.

NATCHER, D.C., DAVIS, S., and HICKEY, C.G. 2005. Comanagement: Managing relationships, not resources. Human Organization 64(3):240-250. 
NUNAVUT. 2003. Wildlife Act. Statutes of Nunavut, c 26.

NWMB (NUNAVUT WILDLIFE MANAGEMENT BOARD). 1999a. Rules of practice for public hearings of the Nunavut wildlife management board. Iqaluit: NWMB.

. 1999b. Submission of the Nunavut Wildlife Management Board to the five-year independent review of the Nunavut land claims agreement and the implementation contract. Iqaluit: NWMB.

2001. Operating procedures, May 1997. Revised November 2001. Iqaluit: NWMB.

- 2004. Annual report 2004. Available online at http:// www.nwmb.com/English/resources/publications.php.

RODON, T. 2003. En partenariat avec l'état: Les expériences de cogestion des autochtones du Canada. Quebec: Les Presses de l'Université Laval.

SPAK, M. 2005. The position of indigenous knowledge in Canadian co-management organizations. Anthropologica 47(2):233-246.
STEVENSON, M.G. 1996. Indigenous knowledge in environmental assessment. Arctic 49(3):278-291.

2004. Decolonizing co-management in northern Canada. Cultural Survival Quarterly 28(1):68-71.

URQUHART, D., ed. 2001. Two Eyes: One Vision, conference summary. Whitehorse: Yukon Fish and Wildlife Management Board.

USHER, P.J. 2000. Traditional ecological knowledge in environmental assessment and management. Arctic 53(2):183-193.

WEBER, M. 1946. From Max Weber: Essays in sociology. Edited and translated by H.H. Gerth and C. Wright Mills. New York: Oxford University Press.

WENZEL, G.W. 1999. Traditional ecological knowledge and Inuit: Reflections on TEK research and ethics. Arctic 52(2):113-124.

WESSENDORF, K. 2001. Traditional knowledge and authority in Nunavut. Paper presented at the Fourth International Congress of Arctic Social Sciences (ICASS IV), 16-20 May 2001, Quebec City, Canada. 